\title{
Comments on Alentorn-Geli et al.: Anteromedial portal versus transtibial drilling techniques in ACL reconstruction: a blinded cross-sectional study at two- to five-year follow-up
}

\author{
Sunil Gurpur Kini
}

Received: 6 June 2010 / Accepted: 7 August 2010 /Published online: 24 August 2010

(C) Springer-Verlag 2010

Dear Editor,

I read the article "Anteromedial portal versus transtibial drilling techniques in ACL reconstruction: a blinded cross-sectional study at two- to five-year follow-up" by Alentorn-Geli et al. [1] in International Orthopaedics with great interest.

While the authors have compared the transtibial and anteromedial techniques for femoral drilling and reported an improved outcome with the anteromedial technique, one of the major factors for the inferior results with the transtibial technique could be the overly vertical orientation of the tibial starting point of $20^{\circ}$ coronal angulation in their study. Howell et al. [2], Chhabra et al. [3] and Golish et al. [4] in their independent studies have shown consistently good results with transtibial techniques when the coronal angulation was aimed at $60-70^{\circ}$ resulting in a more anatomical and oblique femoral tunnel. The study by Bedi et al. [5] showed that the marginal gain in potential obliquity of about $7^{\circ}$ by the anteromedial portal technique may be accompanied by an increased risk of complications, including critically short tunnel length and posterior tunnel wall compromise.

Also a pertinent issue is the relation of the tunnel length and posterior blowout with increasing knee flexion. Contrary to most studies that recommend knee hyperflexion to avoid tunnel blowout, Bedi et al. in their cadaveric study have shown that increasing knee flexion with anteromedial

\footnotetext{
S. Gurpur Kini $(\bowtie)$

Department of Orthopaedics, Guru Teg Bahadur Hospital, University College of Medical Sciences,

26, Canara Bank Appartments, South Patel Nagar,

New Delhi 110008, India

e-mail: drsunilkini@gmail.com
}

portal drilling was associated with a significant reduction in tunnel length, increase in coronal obliquity, increase in sagittal obliquity and increased risk of posterior wall blowout. Furthermore, the risk of blowout and short femoral tunnels can be lessened in the anteromedial portal technique by using a freehand technique aiming at the centre of the femoral stump rather than over the top or posterior wall referencing techniques.

Future modifications in both techniques could definitely yield more desirable and consistent results.

Conflict of interest The author declares that he has no conflict of interest.

\section{References}

1. Alentorn-Geli E, Samitier G, Alvarez P, Steinbacher G, Cugat R (2010) Anteromedial portal versus transtibial drilling techniques in ACL reconstruction: a blinded cross-sectional study at two- to fiveyear follow-up. Int Orthop 34:747-754

2. Howell SM, Gittins ME, Gottlieb JE, Traina SM, Zoellner TM (2001) The relationship between the angle of the tibial tunnel in the coronal plane and loss of flexion and anterior laxity after anterior cruciate ligament reconstruction. Am J Sports Med 29:567-574

3. Chhabra A, Diduch DR, Blessey PB, Miller MD (2004) Recreating an acceptable angle of the tibial tunnel in the coronal plane in anterior cruciate ligament reconstruction using external landmarks. Arthroscopy 20:328-330

4. Golish SR, Baumfeld JA, Schoderbek RJ, Miller MD (2007) The effect of femoral tunnel starting position on tunnel length in anterior cruciate ligament reconstruction: a cadaveric study. Arthroscopy 23:1187-1192

5. Bedi A, Raphael B, Maderazo A, Pavlov H, Williams RJ 3rd (2010) Transtibial versus anteromedial portal drilling for anterior cruciate ligament reconstruction: a cadaveric study of femoral tunnel length and obliquity. Arthroscopy 26(3):342-350 